\title{
Effect of Glutamine Supplementation Associated with Probiotics on Salmonella Typhimurium and Nitric Oxide or Glutamine with Perinatal Supplement on Growth Performance and Intestinal Morphology in Broiler Chickens
} \author{
Barton $^{6}$, B M Hargis ${ }^{1}$ and G Tellez ${ }^{1^{*}}$ \\ ${ }^{1}$ Department of Poultry Science, University of Arkansas, Fayetteville, USA \\ ${ }^{2}$ Facultad de Medicina Veterinaria y Zootecnia, Universidad Nacional Autonoma de Mexico \\ ${ }^{3}$ Argentina Vetanco S.A. Chile 33, Vicente López, Buenos Aires, Argentina \\ ${ }^{4}$ Vetanco do Brasil, Rua Raimundo Zanella, 490D Distrito Industrial Flavio Baldissera, Brazil \\ ${ }^{5}$ Nutritionist, Buenos Aires, Argentina \\ ${ }^{6}$ Pacific Vet Group USA Inc., Fayetteville, USA
}

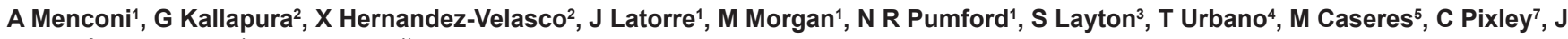

\begin{abstract}
Glutamine-enriched diets have been linked with favorable intestinal effects including structure maintenance of gut barrier against bacteria attacks and enterocyte differentiation. Although post hatch, immaturity of the GIT in the first week is a limiting factor, early nutrition has shown to be an alternative to alleviate the adverse performance effects of post-hatch starvation. In addition, both live and spore based probiotics have earned tremendous attention as a viable control of enteric pathogens. Present studies were carried out with objectives of evaluating the influence of nutrition and synergistic effects of GIn supplementation in combination with FloraMax-B11 (FM), a defined lactic acid bacteria (LAB) probiotic product; PHL-NP-122, a heat-resistant spore-forming Bacillus subtilis (BS); and EarlyBird (EB), a natural hydration and nutrition supplement for neonatal broilers and poults, on Salmonella Typhimurium colonization. Morphometric analysis showed increased $(\mathrm{P}<0.05)$ villus height, villus width, and villus surface area index in chickens treated with all combination groups. A reduction $(P<0.05)$ on nitric oxide (NO) produced was observed in the explant tissues of all the treated groups in comparison with the control group and a synergistic effect $(P<0.05)$ in the groups treated with GIn and BS (HPL-NP-122). Reductions in Salmonella recovery incidence $(P<0.05)$ and colonization $(P<0.05$ to $P<0.001)$ were also observed among the treated groups, suggesting beneficial effects of these combinational feed supplements. Improved gut morphology and Salmonella exclusion was very well supported by body weight $(\mathrm{BW})$ data with lower $(\mathrm{P}<0.05)$ early BW loss and overall BW gains in birds treated with treated groups. Considering the fact that the feed costs represents from 70 to $80 \%$ of the poultry production and the integrity of the epithelial cells of the mucosa, hence ensured good performance and production, is dependent of feed and feed supplements, these studies hold their relevance and importance as beneficial in more than one aspect to the poultry industry.
\end{abstract}

Keywords: Glutamine; Early feeding; Probiotics; Salmonella typhimurium; Broiler; Gut morphology; Performance

\section{Introduction}

The amino acid glutamine (Gln) is traditionally considered as a non-essential amino acid. However, several researches has shown that Gln may be a conditionally essential amino acid in maintaining gut integrity and reducing inflammation [1-5]. Glutamine-enriched diets have been linked with favorable intestinal effects including maintenance of gut barrier function and enterocyte differentiation [6]. Glutamine has also been the focus of many studies in physiology and medicine due to its important pleiotropic roles in metabolism and tissue homeostasis. Glutamine serves as an essential metabolic precursor in nucleotide, glucose and amino sugar biosynthesis, glutathione homeostasis and protein synthesis [3]. Presence of two mobilizable Nitrogen $(\mathrm{N})$ groups in its structure, Gln can function as a vehicle for the tissue exchange of $\mathrm{N}$ and perform a crucial role in several important metabolic pathways.

Functions of Gln in mucosal barrier is exclusively studied. It is responsible for mucosa structure maintenance, through mucin synthesis and the maintenance of a barrier against bacteria attacks, in addition to promoting the maturity and integrity of the intestinal flora associated with the immune system. Because Gln is the main metabolite that nourishes the enterocytes, effect of glutamine supplementation on reconstitution of the intestinal mucosa, after some damage, has been investigated in various studies [2]. In addition, Gln is an essential substrate in the construction of the passive barrier of mucin to bacteria because it is necessary for the synthesis of $\mathrm{N}$ bases and amino sugars of the extracellular matrix, $\mathrm{N}$-acetylglucosamine and $\mathrm{N}$-acetylgalactosamine, and for the glycosylation of mucins [1]. Gln has direct action in the elimination of free radicals by being a precursor of glutathione synthesis [6]. Gln is also considered as an immunonutrient, because of its capability of upregulating or downregulating immune responses to a pathogen or disease condition and may therefore reduce

*Corresponding author: Guillermo Tellez, Department of Poultry Science University of Arkansas, Fayetteville, AR 72701, USA, Tel: (479) 575-3256; E-mail: gtellez@uark.edu

Received May 25, 2013; Accepted June 13, 2013; Published June 17, 2013

Citation: Menconi A, Kallapura G, Hernandez-Velasco X, Latorre J, Morgan M, et al, (2013) Effect of Glutamine Supplementation Associated with Probiotics on Salmonella Typhimurium and Nitric Oxide or Glutamine with Perinatal Supplement on Growth Performance and Intestinal Morphology in Broiler Chickens. Clin Microbial 2: 120. doi:10.4172/2327-5073.1000120

Copyright: (c) 2013 Menconi A, et al. This is an open-access article distributed under the terms of the Creative Commons Attribution License, which permits unrestricted use, distribution, and reproduction in any medium, provided the original author and source are credited. 
Citation: Menconi A, Kallapura G, Hernandez-Velasco X, Latorre J, Morgan M, et al, (2013) Effect of Glutamine Supplementation Associated with Probiotics on Salmonella Typhimurium and Nitric Oxide or Glutamine with Perinatal Supplement on Growth Performance and Intestinal Morphology in Broiler Chickens. Clin Microbial 2: 120. doi:10.4172/2327-5073.1000120

pathogen levels. As an immunonutrient, Gln is important for promoting the integrity and maturation of intestinal microflora associated with the immune system, for enhancing mucin synthesis to maintain intestinal mucosa structure, and for reinforcing the epithelial barrier against bacterial attacks [7].

From a poultry production perspective, the maintenance, development and health of GIT are fundamental, since GIT possesses the functions of food content storage, secretion digestion, and absorption of nutrients. The egg supplies nutrients during embryonic development. These gut functions begin with hatching and has to be maintained throughout the production pyramid. Posthatch the gut maturation process begins and this is a critical point in determining the poultry performance. The first two weeks of post hatch are even critical and represent approximately $30 \%$ of the useful life of the bird, considering a 6 week production cycle. Morphological studies by Sell et al. (1991) [8] point out that at the moment of hatching, the weight of the small intestine represents 1.2 to $2.6 \%$ of the BW of the bird and 6.2 to $6.6 \%$ at maximum development (between $\mathrm{d} 5$ and 7 post hatch) [6]. Hence the immaturity of the GIT in the first week post hatch is a limiting factor, since major gut transitions like increase in absorption capacity with a relative increase in the area of absorption through the longitudinal growth of the intestine, and increase in the height of the villi, proper secretion of enzymes, are events yet to happen. In this regard, we suggest and hypothesize that the stimulation of the GIT by different substrates, soon after hatching, can accelerate its development.

On the other hand, delaying access to feed and water has been documented to increase susceptibility to pathogens and cause weight loss, leading to poorly starting flocks with reduced weight gains and mortality [9-11]. Early nutrition has been widely studied in poultry, and it has been shown that the use of early feeding supplements alleviates the adverse performance effects of post-hatch starvation [12-15], as well as stimulates yolk utilization [16], intestinal maturation [10], development of homeothermy $[17,18]$, and retain passive immunity [19]. In this concern, Early Bird (EB), a natural hydration and nutrition supplement for neonatal broilers and poults, is extensively used to promote instinctive feeding of birds, that leads to a rapid onset and increased early weight gains that will eventually be maintained throughout the bird's lifetime [20].

Alternatively, increasing socio-political concerns with antibiotic usage have led to investigations of potential alternatives for food safety and growth promotion. Both live and spore based probiotics have earned tremendous attention as a viable control of enteric pathogens in this regard. Laboratory and field research conducted by our laboratory with a defined lactic acid bacteria (LAB) probiotic, FloraMax-B11 (FM) have proved extremely influential in accelerated development of normal microflora and reduction in Salmonella colonization, in commercial poultry [21-28]. More recently, we have confirmed that selected heatresistant spore-forming Bacillus species, PHL-NP-122, can markedly reduce Salmonella and Clostridium in poultry when administered in very high numbers [29-31].

The present studies hold their relevance and importance, considering the fact that the feed costs represents 70 to $80 \%$ of the poultry production and the integrity of the epithelial cells of the mucosa, hence ensured good performance and production, is dependent of feed and feed supplements. These studies were carried out with multiple objectives of evaluating the influence of nutrition and combinational effects of Gln supplementation in concert with FloraMax-B11 (FM), PHL-NP-122 and $\mathrm{EB}$ on Salmonella typhimurium colonization. $\mathrm{EB}+\mathrm{Gln}$ were used to evaluate their combined effects on neonatals, FM+Gln and PHL-
NP-122+Gln were used to evaluate their effects in relatively older birds. These studies also supports numerous trials which have previously tested individual positive effects of Gln, EB, FM and PHL-NP-122, on growth performance by rapid development of intestinal morphology in broiler chickens [20-31]. In addition, inflammatory marker like nitric oxide was also measured to know the combinational effects on Salmonella typhimurium induced inflammatory damage.

\section{Materials and Methods}

\section{Animal source and diets}

Day-of-hatch, off-sex broiler chickens were obtained from CobbVantress (Siloam Springs, AR, USA) for all the trials mentioned below. All animal handling procedures were in compliance with Institutional Animal Care and Use Committee at the University of Arkansas. In all experiments, diets were fed in mash form, and were formulated to exceed National Research Council [32] estimated nutrient requirements. The common starter diet was a typical corn soy bean meal diet (chemical analysis of nutrients is presented in Table 1). For experiments 2 and 3 , the diet with glutamine was similar to the common starter diet but was supplemented with $1 \%$ Gln.

\begin{tabular}{|c|c|c|}
\hline Item & Glutamine free & Glutamine $1 \%$ \\
\hline \multicolumn{3}{|l|}{ Ingredient } \\
\hline Corn & 546.389 & 546.389 \\
\hline Soybean meal & 369.359 & 369.359 \\
\hline Vegetable oil & 33.231 & 33.231 \\
\hline Dicalcium phosphate & 15.855 & 15.855 \\
\hline Calcium carbonate & 14.44 & 14.44 \\
\hline Salt & 3.538 & 3.538 \\
\hline DL-Methionine & 2.56 & 2.56 \\
\hline Vitamin premix $^{1}$ & 1.0 & 1.0 \\
\hline Solka-floc & 10.0 & -- \\
\hline L-Lysine $\mathrm{HCl}$ & 0.977 & 0.977 \\
\hline L-Glutamine & --- & 10.00 \\
\hline Choline chloride $60 \%$ & 1.00 & 1.00 \\
\hline Mineral premix ${ }^{2}$ & 0.500 & 0.500 \\
\hline Zinc bacitracin & 0.500 & 0.500 \\
\hline Sodium monensin & 0.500 & 0.500 \\
\hline Antioxidant $^{3}$ & 0.150 & 0.150 \\
\hline \multirow[t]{2}{*}{ Total } & 1000 & 1000 \\
\hline & \multicolumn{2}{|l|}{ Calculated analysis } \\
\hline $\mathrm{ME}, \mathrm{kcal} / \mathrm{kg}$ & 3,035 & 3,035 \\
\hline CP, \% & 21.704 & 21.704 \\
\hline Lysine, \% & 1.328 & 1.328 \\
\hline Methionine, \% & 0.597 & 0.597 \\
\hline Met + cist, \% & 0.98 & 0.98 \\
\hline Threonine, \% & $0 . .866$ & $0 . .866$ \\
\hline Tryptophan, \% & 0.282 & 0.282 \\
\hline Total calcium, \% & 0.900 & 0.900 \\
\hline Available phosphorus, \% & 0.450 & 0.450 \\
\hline Sodium, \% & 0.160 & 0.160 \\
\hline
\end{tabular}

${ }^{1}$ Vitamin premix supplied the following per kg: vitamin A, 20,000,000 IU; vitamin D3, 6,000,000 IU; vitamin E, 75,000 IU; vitamin K3, $9 \mathrm{~g}$; thiamine, $3 \mathrm{~g}$; riboflavin, 8 $\mathrm{g}$; pantothenic acid, $18 \mathrm{~g}$; niacin, $60 \mathrm{~g}$; pyridoxine, $5 \mathrm{~g}$; folic acid, $2 \mathrm{~g}$; biotin, $0.2 \mathrm{~g}$; cyanocobalamin, $16 \mathrm{mg}$; and ascorbic acid, $200 \mathrm{~g}$.

${ }^{2}$ Mineral premix supplied the following per kg: manganese, $120 \mathrm{~g}$; zinc, $100 \mathrm{~g}$; iron $120 \mathrm{~g}$; copper, 10-15 g; iodine, $0.7 \mathrm{~g}$; selenium, $0.4 \mathrm{~g}$; and cobalt, $0.2 \mathrm{~g}$.

${ }^{3}$ Ethoxyquin.

Table 1: Composition of the starter diet for broiler chickens from 1 to $14 \mathrm{~d}(\mathrm{~kg})$. 
Citation: Menconi A, Kallapura G, Hernandez-Velasco X, Latorre J, Morgan M, et al, (2013) Effect of Glutamine Supplementation Associated with Probiotics on Salmonella Typhimurium and Nitric Oxide or Glutamine with Perinatal Supplement on Growth Performance and Intestinal Morphology in Broiler Chickens. Clin Microbial 2: 120. doi:10.4172/2327-5073.1000120

\section{Perinatal supplement and probiotic culture}

EarlyBird (EB), is an all-natural hydration and nutrition supplement for young birds. One $g$ of EB contains $64 \%$ of water, $22.0 \%$ of protein, $10 \%$ of fiber, $20 \%$ carbohydrate and less than $2.2 \%$ of fat (Pacific Vet Group USA Inc., Fayetteville AR 72703). Each bird should be administered $2 \mathrm{~g}$ of EB according to manufacturer's instructions. FloraMax B-11 (FM) is a probiotic culture derived from poultry, consisting of 2 strains of LAB isolates: Lactobacillus salivarius and Pediococcus parvulus (Pacific Vet Group USA Inc., Fayetteville AR 72703) was used as drinking water administration. Bacillus subtilis (BS) spores (PHL-NP-122) previously identified as potential probiotic or direct-fed microbial (DFM) candidate [31] was used in the present study.

\section{Bacterial strain and culture conditions}

The challenge organism used in all experiments was poultry isolate of Salmonella enterica subspecies enterica serovar Typhimurium (ST). This isolate was selected for resistant to $25 \mu \mathrm{g} / \mathrm{mL}$ of novobiocin (NOV, catalog no.N-1628, Sigma) and $20 \mu \mathrm{g} / \mathrm{mL}$ of nalidixic acid (NA, catalog no.N-4382, Sigma) in our laboratory. For the present studies, $100 \mu \mathrm{L}$ of SE from a frozen aliquot was added to $10 \mathrm{~mL}$ of tryptic soy broth (Catalog no. 22092, Sigma) and incubated at $37^{\circ} \mathrm{C}$ for $8 \mathrm{~h}$, and passed every $8 \mathrm{~h}$ to ensure that all bacteria were in log phase. Post incubation, bacterial cells were washed 3 times in sterile $0.9 \%$ saline by centrifugation at $1,864 \times g$, quantified with a spectrophotometer (Spectronic 20D+, Spectronic Instruments Thermo Scientific) and diluted in sterile $0.9 \%$ saline to a concentration of approximately $10^{8}$ $\mathrm{cfu} / \mathrm{mL}$. Concentrations of ST were determined retrospectively by serial dilution and further plating on Brilliant Green Agar (BGA, Catalog no. 70134, Sigma) with NOV and NA agar for enumeration of actual colony forming units (cfu) used to challenge the chickens.

\section{Experimental Design}

\section{Experiment 1}

This experiment evaluated the effect of L-Glutamine (Catalog no. BDH 4514-1KGP, VWR West Chester, PA 19380) supplementation associated with FM in the drinking water on ST cecal colonization. Day-of hatch off sex broiler chickens were obtained and randomly distributed into 4 separate groups with 25 birds per group: Group 1, Control ST challenged; Group 2, 10\% L-Glutamine (Gln) mixed in the drinking water; Group 3, FM mixed in the drinking water; Group 4, Gln + FM mixed in the drinking water. A small number of chickens $(n=20)$ were humanely killed on arrival, ceca-cecal tonsils and liver and spleen were aseptically removed, cultured in tetrathionate enrichment broth (Tet, Catalog no. 210420, Becton Dickinson, Sparks, MD) and confirmed negative for Salmonella by plating the samples on to selective BGA with NOV. All groups were challenged with ST at $10^{5} \mathrm{cfu} / \mathrm{bird}$. One h post challenge, groups 2, 3 and 4 received their treatment in the drinking water, while group 1 acted as positive control for ST. Twenty chickens from control or treated groups were humanly killed and cultured at $24 \mathrm{~h}$, for ST recovery in ceca-cecal tonsils and enumerated as explained later.

\section{Experiment 2}

This experiment evaluated the effect of $1 \%$ dietary Gln supplementation for 6 days associated with FM in the drinking water on ST cecal colonization and in vitro nitric oxide production. Day-of hatch off sex broiler chickens were obtained and randomly distributed into 4 separate groups with 25 birds per group: Group 1, Control ST challenged; Group 2, 1\% dietary Gln; Group 3, FM mixed in the drinking water following manufacture instructions; Group 4, 1\% dietary Gln + FM mixed in the drinking water following manufacture instructions. A small number of chickens $(n=20)$ were humanely killed on arrival, ceca-cecal tonsils and liver and spleen were aseptically removed, cultured in Tet and confirmed negative for Salmonella by plating the samples on to selective BGA with NO. At five days of age, all groups were challenged with $\mathrm{ST}$ at $10^{6} \mathrm{cfu} / \mathrm{bird}$. One h post challenge, groups 3 and 4 received FM in the drinking water, while group 1 acted as positive control for ST. Twelve chickens from control or treated groups were humanly killed and cultured at six days of age ( $24 \mathrm{~h}$ post ST challenge), for ST enumeration and explant samples for nitric oxide determination as explained later.

\section{Experiment 3}

This experiment evaluated the effect of $1 \%$ dietary Gln supplementation for 6 days associated with BS spores (PHL-NP-122) on ST cecal colonization and in vitro nitric oxide production. Day-of hatch off sex broiler chickens were obtained and randomly distributed into 4 separate groups with 25 birds per group: Group 1, Control ST challenged; Group 2, 1\% dietary Gln; Group 3, PHL-NP-122 with a concentration of $10^{6} \mathrm{BS}$ spores/g of feed ; Group 4, 1\% dietary Gln + PHL-NP-122 with a concentration of $10^{6} \mathrm{BS}$ spores/g of feed. A small number of chickens $(n=20)$ were humanely killed on arrival, ceca-cecal tonsils and liver and spleen were aseptically removed, cultured in Tet and confirmed negative for Salmonella by plating the samples on to selective BGA with NOV. At five days of age, all groups were challenged with ST at $10^{6} \mathrm{cfu} / \mathrm{bird}$. Twelve chickens from control or treated groups were humanly killed and cultured at six days of age ( $24 \mathrm{~h}$ post ST challenge), for ST enumeration and explant samples for nitric oxide determination as explained later.

\section{Experiment 4}

This experiment evaluated the effect of $0.5 \%$ Gln supplemented with perinatal supplement on growth performance and intestinal morphology in broiler chickens during 14 days. Three hundred off sex broiler chicks were obtained and transported to the University of Arkansas facility where they were identified through neck tags and randomly distributed in to 3 groups of 100 birds each, into commercial plastic poultry transport crates: Group 1, received no treatment; Group 2, received 200 g of EB only; and Group 3 received $0.5 \%$ Gln supplemented with EB. Perinatal supplement was administered according to manufacturer's instructions. All birds were kept fasted, with no feed or water, for 48 $\mathrm{h}$ under simulated shipping conditions, at room temperature (25.5 ${ }^{\circ} \mathrm{C}$ ) maintained with constant air flow to ensure the chicks were comfortable. After $48 \mathrm{~h}$ under simulated shipping conditions, chicks were placed onto floor pens with fresh wood shavings with a stocking density of $0.15 \mathrm{~m}^{2} /$ chick. Age appropriate environmental temperatures were maintained and supplemental heat lamps were provided for each pen. Chickens were provided ad libitum access to water and a balanced un-medicated corn-soybean diet meeting or exceeding the nutrition requirements of poultry recommended NRC [32]. All birds were weighed at 24 h, 48 h, 7 days and 14 days of age. Recorded body weights (BW) were then used to determine either body weight loss (BWL) at $24 \mathrm{~h}$ and $48 \mathrm{~h}$ or body weight gain (BWG) at 7 and 14 days of age. Five ileum and duodenum samples from each group were collected for enteric morphometric analysis of mucosal development at $48 \mathrm{~h}, 7$ and 14 days, processed and analyzed further as explained below.

\section{Salmonella Recovery}

In experiment one, chickens were humanely killed by $\mathrm{CO}_{2}$ 
Citation: Menconi A, Kallapura G, Hernandez-Velasco X, Latorre J, Morgan M, et al, (2013) Effect of Glutamine Supplementation Associated with Probiotics on Salmonella Typhimurium and Nitric Oxide or Glutamine with Perinatal Supplement on Growth Performance and Intestinal Morphology in Broiler Chickens. Clin Microbial 2: 120. doi:10.4172/2327-5073.1000120

asphyxiation; ceca-ceca tonsils were aseptically removed to culture and enumerate Salmonella. Briefly, samples were placed in $10 \mathrm{~mL}$ of Tet for enrichment and incubated at $37^{\circ} \mathrm{C}$ for 24 hours. Samples were then plated on BGA NO and NA plates and incubated at $37^{\circ} \mathrm{C}$ for 24 $\mathrm{h}$ to confirm presence/absence of typical lactose-negative colonies of Salmonella. Ceca were homogenized and diluted with saline (1:4 by $\mathrm{wt} / \mathrm{vol}$ ) and tenfold dilutions were plated on BGA with NO and NA, incubated at $37^{\circ} \mathrm{C}$ for $24 \mathrm{~h}$ to enumerate total Salmonella cfu. Later, the cecal samples were enriched in double strength Tet and further incubated at $37{ }^{\circ} \mathrm{C}$ for 24 hours. Following this, ceca enrichment samples were plated on to BGA NO and NA plates and incubated at $37^{\circ} \mathrm{C}$ for $24 \mathrm{~h}$ to confirm presence/absence of typical lactose-negative colonies of Salmonella. This enumeration procedure was also conducted in experiments two and three.

\section{Explant Culture}

A novel explant culture method for rapid quantification of nitrite as an inflammatory marker developed in our lab [Kallapura et al., 2013, Submitted for Publication] was employed here. Briefly, the entire ileum was aseptically removed, cleaned by infusing sterile $0.9 \%$ saline through the ileal section to remove all the ingesta. The cleansed ileum section was then incised longitudinally exposing the mucosal surface. Ileal sections $\left(0.5 \mathrm{~cm}^{2}\right)$ were made using a sterile surgical blade and placed in a 24 well culture plate. Care was taken in placing the tissue explants, with the serosa facing down and in contact with the well bottom and the mucosa facing up, exposed to the media components. Circular metal meshes measuring approximately $7.5 \mathrm{~mm}$ in radius with $3 \mathrm{~mm}$ height were used to keep the floating explants in place. These meshes were made of steel $316 \mathrm{~L}$, the same material used in construction of fermenters and bioreactors. The material is non-reactive, non-additive, non-absorptive and non-corrosive and hence a safe choice to be used with a culture medium. Further care was taken to autoclave these meshes before use, to avoid any contamination. Explants $(n=12)$ for each group were obtained, with one ileal explant per chicken. The ileal explants cultured in 24 well culture plates were then transferred to a laminar airflow hood and $1 \mathrm{~mL}$ of RPMI 1640 medium with 5\% bovine serum, $1.5 \mathrm{mM} \mathrm{L}$ - glutamine, and $1 \mathrm{~mL}$ of antibiotic - antimycotic solution (containing 10,000 units of penicillin, $10 \mathrm{mg}$ streptomycin and $25 \mu \mathrm{g}$ amphotericin - Sigma-aldrich, St. Louis, MO) was added to each well. The cultures were further incubated at $40{ }^{\circ} \mathrm{C}, 5 \% \mathrm{CO}_{2}$ and culture supernatants were collected for the nitrite assay at 3,6 and $12 \mathrm{~h}$ post incubation.

\section{Nitrite Assay}

The Greiss reaction assay, which colorimetrically quantifies nitrite, was used to measure the nitrite accumulated over time in the culture medium, which served as an indirect measure of NO produced by the explants. The assay was carried out in a 96 well microtitre plate to which $100 \mu \mathrm{L}$ of culture supernatant from the explant culture (at 3, 6, and $12 \mathrm{~h}$ ) was added in triplicates, followed by an equal volume of Greiss reagents. First, $50 \mu \mathrm{L}$ of $1 \%$ sulfanilamide (Sigma-aldrich, St. Louis, MO) in $5 \%$ phosphoric acid, was added and incubated at room temperature for $10 \mathrm{~min}$ followed by $50 \mu \mathrm{L}$ of $0.1 \% \mathrm{~N}$-(1-napthyl) ethylenediamine dihydrochloride (Sigma-aldrich, St. Louis, MO) in water and incubated further for a visible colored reaction to develop and measured at 540 $\mathrm{nm}$. The Greiss reaction was based on a two-step diazotization reaction in which acidified nitrite (phosphoric acid) produces a nitrosating agent which reacts with sulfanilic acid to produce a diazonium ion. This ion intermediate was then coupled with $\mathrm{N}$-(1-naphthyl) ethylenediamine to form the chromophoric azo-derivative whose absorbance was measured at $540 \mathrm{~nm}$. Optical density (OD) for each explant sample was compared to known amounts of sodium nitrite $(1.25,2.5,5,10,20,30$, $40,50,60,70,80$, and $90 \mu \mathrm{M})$ and extrapolated using a standard curve equation.

\section{Intestinal Morphological Analysis}

For enteric morphometric analysis, birds on the designated evaluation day were euthanized, and ileum and duodenum samples were collected $(n=5)$. A $1-\mathrm{cm}$ segment of the midpoint of the duodenum and the distal end of the lower ileum from each bird was removed and fixed in $10 \%$ buffered formaldehyde for $48 \mathrm{~h}$. Each of these intestinal segments was embedded in paraffin, and a $5-\mu \mathrm{m}$ section of each sample was placed on a glass slide and stained with hematoxylin and eosin for examination under a light microscope. All morphological parameters were measured using the ImageJ software package (http://rsb.info.nih. gov/ij/). Ten replicate measurements for each variable studied, were taken from each sample and the average values were used in statistical analysis. Villus length (VL) was measured from the top of the villus to the top of the lamina propria. Villus width (VW) was measured at the widest area of each villus [33]. Villus surface area (VS) was calculated using the formula $(2 \pi)(\mathrm{VW} / 2)(\mathrm{VL})[34]$.

\section{Statistical Analysis}

Any statistical differences in BW, BWL, BWG, $\log _{10}$ SE cfu/g of ceca and morphometric measurements were determined by analysis of variance using the General Linear Models (proc GLM) procedure using commercial SAS ${ }^{\bigotimes}$ statistical software [35]. Significant differences set at $P<0.05$, were further separated using Duncan's multiple range test. The percent recovery of Salmonella was compared using the chi-square test of independence testing all possible group combinations to determine significance for these studies [36].

\section{Results}

The results of the effect of $10 \%$ Gln supplementation associated with FM in the drinking water on ST colonization in broiler chickens from experiment 1 are summarized in table 2. A $20 \%$ significant reduction $(P<0.05)$ in the rate of intestinal colonization of ST at 24 $\mathrm{h}$ were observed in the group that received $10 \%$ Gln in the drinking water; and the group that receive $10 \% \mathrm{Gln}+\mathrm{FM}$ had a $35 \%$ reduction of ST $(\mathrm{P}<0.01)$. However, the group that received just the probiotic in the drinking water showed a $65 \%$ ST reduction when compared with control group $(\mathrm{P}<0.001)$. A similar trend in the reduction of cfu of ST/g of ceca content was observed in the same groups (Table 2).

The effect of $1 \%$ dietary Gln supplementation associated with FM in the drinking water on ST colonization at 6 days of age in broiler chickens

\begin{tabular}{|l|c|c|}
\hline Treatment & Cecal tonsil & Log $_{10}$ S. Typhimurium /g of ceca content \\
\hline 1. Control ST & $20 / 20(100 \%)$ & $3.120 .21^{\mathrm{a}}$ \\
\hline 2. GIn $10 \%$ & $16 / 20(80 \%)^{\mathrm{x}}$ & $1.96 \pm 0.44^{\mathrm{ab}}$ \\
\hline 3. FM & $7 / 20(35 \%)^{\mathrm{y}}$ & $0.67 \pm 0.35^{\mathrm{c}}$ \\
\hline 4. GIn $10 \%+$ FM & $13 / 20(65 \%)^{\mathrm{z}}$ & $1.72 \pm 0.55^{\mathrm{bc}}$ \\
\hline
\end{tabular}

Chickens were orally gavaged with $10^{5} \mathrm{cfu}$ of $\mathrm{S}$. Typhimurium /chicken at hatch One hour later chickens were treated in the drink water. Control chickens received regular water. Twenty chickens from each group were humanly killed and cultured $24 \mathrm{~h}$ post challenge, for ST recovery. Data of cecal tonsils is expressed as positive/ total chickens (\%). ${ }^{\times} \mathrm{P}<0.05 ;$ y $\mathrm{P}<0.01$; ${ }^{\mathrm{P}} \mathrm{P}<0.001$.

Ceca from twelve chickens were enumerated. $\log _{10}$ S. typhimurium/g of ceca content data is expressed as mean \pm standard error. $a, b, c$ Treatments values with no common superscript differ significantly $\mathrm{P}<0.05$.

Table 2: Effect of $10 \%$ glutamine (GIn) supplementation associated with FloraMax (FM) in the drinking water on Salmonella Typhimurium (ST) colonization in broiler chickens from experiment 1 . 
Citation: Menconi A, Kallapura G, Hernandez-Velasco X, Latorre J, Morgan M, et al, (2013) Effect of Glutamine Supplementation Associated with Probiotics on Salmonella Typhimurium and Nitric Oxide or Glutamine with Perinatal Supplement on Growth Performance and Intestinal Morphology in Broiler Chickens. Clin Microbial 2: 120. doi:10.4172/2327-5073.1000120

Page 5 of 7

from experiment 2 are summarized in table 3. A significant reduction on ST/g of ceca content was observed in both, dietary Gln alone or probiotic alone groups. This reduction was associated with a significant reduction on NO produced in the explant tissues as compared with the control group. However, an even more significant reduction on ST/g of ceca content and synergistic effect in the reduction of NO production was observed in the group that received the inclusion of $1 \%$ dietary Gln and FM in the drinking water when compared with the control group (Table 3).

The effect of $1 \%$ dietary Gln supplementation associated with PHL-NP-122 on ST colonization at 6 days of age in broiler chickens from experiment 3 is summarized in table 4 . A significant reduction on ST/g of ceca content was observed in both, dietary Gln or PHLNP-122 groups. As in the previous experiment, this reduction was also associated with a significant reduction on NO produced in the explant tissues as compared with the control group. However, an even more significant reduction on ST/g of ceca content and synergistic effect in the reduction of NO production was observed in the group that received

\begin{tabular}{|c|c|c|}
\hline Treatment & $\log _{10} \mathrm{ST} /$ & Nitrite in $\mu \mathrm{M}$ \\
\hline Control ST & $6.1 \pm 0.2^{a}$ & $35.0 \pm 25.1^{a}$ \\
\hline 2. Glu $1 \%$ & $6.0 \pm 0.2 b c$ & $6.6 \pm 2.0^{b}$ \\
\hline 3. $\mathrm{FM}$ & $6.3 \pm 0.3 \mathrm{ab}$ & $8.4 \pm 2.3^{b}$ \\
\hline 4. Glu $1 \%+F M$ & $4.9 \pm 0.11^{d}$ & $4.8 \pm 1.4^{b}$ \\
\hline
\end{tabular}

Chickens were orally gavaged with $10^{6} \mathrm{cfu}$ of S. typhimurium /chicken at five days of age. One hour later chickens in groups 3 and 4 were treated in the drink water with FM. Twelve chickens/group were humanly killed and cultured $24 \mathrm{~h}$ post challenge for ST recovery and explant ileal samples. $\log _{S} S$. Typhimurium/g of ceca content or micro molar $(\mu \mathrm{M})$ amounts of nitrite, data is expressed as mean \pm standard error. a, b, cTreatments values with no common superscript within columns differ significantly $\mathrm{P}<0.05$

Table 3: Effect of $1 \%$ dietary glutamine (Gln) supplementation associated with FloraMax (FM) in the drinking water on Salmonella typhimurium (ST) colonization at 6 days of age in broiler chickens from experiment 2 .

\begin{tabular}{|l|c|c|}
\hline \multicolumn{1}{|c|}{ Treatment } & $\begin{array}{c}\log _{10} \text { ST/ } \\
\text { g of ceca content }\end{array}$ & $\begin{array}{c}\text { Nitrite in } \mu \mathrm{M} \\
\text { at } \mathbf{6 ~ h}\end{array}$ \\
\hline 1. Control ST & $6.9 \pm 0.2^{\mathrm{a}}$ & $34.8 \pm 25.4^{\mathrm{a}}$ \\
\hline 2. Glu 1\% & $6.1 \pm 0.2^{\mathrm{b}}$ & $6.6 \pm 1.9^{\mathrm{b}}$ \\
\hline 3. PHL-NP-122 & $6.0 \pm 0.1^{\mathrm{b}}$ & $5.1 \pm 0.8^{\mathrm{b}}$ \\
\hline 4. Glu 1\% + PHL-NP-122 & $5.6 \pm 0.3^{\mathrm{c}}$ & $2.4^{\mathrm{b}} \pm 0.5^{\mathrm{c}}$ \\
\hline
\end{tabular}

Chickens were orally gavaged with $10^{6} \mathrm{cfu}$ of $\mathrm{S}$. Typhimurium/chicken at five $\mathrm{d}$ of age. Twelve chickens from each group were humanly killed and cultured $24 \mathrm{~h}$ post challenge, for ST recovery and explant ileal samples. $\log _{10} S$. Typhimurium/g of ceca content or micro molar $(\mu \mathrm{M})$ amounts of nitrite, data is expressed as mean \pm standard error. a, b, c Treatments values with no common superscript within columns differ significantly $\mathrm{P}<0.05$.

Table 4: Effect of $1 \%$ dietary glutamine (Gln) supplementation associated with Bacillus subtilis spores (PHL-NP-122) on Salmonella Typhimurium (ST) colonization at 6 days of age in broiler chickens from experiment 3.

\begin{tabular}{|c|c|c|c|c|c|c|c|c|c|}
\hline Treatments & Initial BW & $\begin{array}{c}\text { BW at } \\
24 \mathrm{~h}\end{array}$ & $\begin{array}{c}\text { BWL } \\
\text { at24 h }\end{array}$ & $\begin{array}{c}\text { BW at } \\
48 \mathrm{~h}\end{array}$ & $\begin{array}{c}\mathrm{BWL} \\
\text { at48 h }\end{array}$ & $\begin{array}{c}\text { BW at } \\
7 \mathrm{~d}\end{array}$ & $\begin{array}{l}\text { BWG } \\
\text { at7 d }\end{array}$ & $\begin{array}{c}\text { BW at } \\
14 \mathrm{~d}\end{array}$ & $\begin{array}{l}\text { BWG at } \\
14 \mathrm{~d}\end{array}$ \\
\hline 1. Control & $3.7 \pm 0.3^{a}$ & $40.2 \pm 0.3^{a}$ & $-3.5 \pm 0.1^{b}$ & $38.1 \pm 0.3^{a}$ & $-5.6 \pm 0.1^{b}$ & $111.3 \pm 1.1^{b}$ & $\pm 1.1^{\mathrm{b}}$ & $330.1 \pm 4.7^{b}$ & $288.7 \pm 4.4^{b}$ \\
\hline 2. EB & $43.0 \pm 0.3^{\mathrm{ab}}$ & $41.3 \pm 0.3^{a}$ & $-1.7 \pm 0.1^{b}$ & $38.9 \pm 0.3^{a}$ & $-4.1 \pm 0.4^{b}$ & $118.6 \pm 1.3^{a}$ & $75.4 \pm 1.1^{\mathrm{a}}$ & $344.0 \pm 4.8^{\mathrm{a}}$ & $301.8 \pm 4.2^{\mathrm{a}}$ \\
\hline 3. $\mathrm{Gln}+\mathrm{EB}$ & $42.4 \pm 0.2^{b}$ & $41.2 \pm 0.3^{\mathrm{a}}$ & $-1.2 \pm 0.1^{a}$ & $39.1 \pm 0.3^{a}$ & $-3.3 \pm 0.1^{a}$ & $118.5 \pm 1.4^{a}$ & $76.1 \pm 1.2^{\mathrm{a}}$ & $349.6 \pm 5.7^{a}$ & $306.3 \pm 5.2^{\mathrm{a}}$ \\
\hline
\end{tabular}

300 day of hatch off sex broiler chickens were obtained and randomly distributed into 3 separate groups $(n=100)$. Treatments were administered according to groups: Group 1, received no treatment; Group 2, received $200 \mathrm{~g}$ of EB only; and Group 3 received EB supplemented with $0.5 \% \mathrm{~L}$-glutamine. All birds were weighed at $24 \mathrm{~h}, 48 \mathrm{~h}$ $7 \mathrm{~d}$ and $14 \mathrm{~d}$ of age. Recorded body weights (BW) were then used to determine either BW loss (BWL) at $24 \mathrm{~h}$ and $48 \mathrm{~h}$ or BW gain (BWG) at 7 and $14 \mathrm{~d}$ of age. BW data were expressed as mean $(\mathrm{g}) \pm$ standard error. $\mathrm{a}, \mathrm{b}, \mathrm{c}$ Values within columns with no common superscript differ significantly $\mathrm{P}<0.05$.

Table 5: Effect of Glutamine (GIn) with perinatal supplement (EB) on body weight (BW) and performance of broiler chickens from experiment 4.

the inclusion of $1 \%$ dietary Gln and PHL-NP-122 in the drinking water when compared with the control group (Table 4).

The effect of $0.5 \%$ Gln with perinatal supplement on body weight and performance of broiler chickens from experiment 4 are summarized in Table 5 . At $24 \mathrm{~h}$ and $48 \mathrm{~h}$ significant BWL were observed with control only groups when compared with the group that received EB + with significantly higher BWG seen in the group treated with EB + Gln. It was of significance to mention that by 14 days, the BW of the EB + Gln treated group was, on an average, about $17 \mathrm{~g}$ heavier than that of on-treated control group $(\mathrm{P}<0.05)$. Although not significant, over all, $2 \mathrm{~g}$ heavier than that of non-treated control group (Table 1). The effect f $0.5 \%$ Gln with perinatal supplement on morphological developmen este 6 . ignificantly increased $\mathrm{VH}, \mathrm{VW}$, and VS were observed in the group treated with perinatal supplement only or $0.5 \%$ Gln and perinatal
supplement, when compared to non-treated control group at $24 \mathrm{~h}$. The trend of significant and in some cases numerically, morphometric changes were observed throughout the study in duodenum samples (Table 6). No significant morphometric changes between the three groups were observed in samples from distal ileum (data not shown).

\section{Discussion}

Glutamine is a captivating amino acid that constitutes significant concentrations of muscles and plasma, and represents about 50 to $80 \%$ total free amino acid in the body [1,4,37]. Since its structure contains two mobilizable $\mathrm{N}$ groups Gln is involved in transportation and exchange of $\mathrm{N}$ in the cells, as well as participate in importan . This amino acid is also a key component in the function and structure of the intestinal mucosa since it is involved in mucin synthesis as well as maintaining the integrity of the gut phe $[1,3,4,6,34]$, which has a profound impact in digestive physiology [21,38-40], as well as innate and acquire immunity [41-44] energetic fuel for cells that has a rapid proliferation such as enterocytes, lymphocytes and other cells involved in inflammation [2,3,7,45].

In the present study, the supplementation of $10 \%$ Gln with probiotic culture in the drinking water had a significant reduction on ST colonization in the ceca, but this effect was not synergistic (Table 2). ( bacteria probiotic in the drinking water (Tables 3), or in the diet throw and synergistic effect on the reduction of Salmonella Typhimurium in the ceca. This reduction was associated with a significant reduction of nitric oxide produce in the explant of ileum samples (Table 3 and 4). Quantifying nitrite, a metabolite of nitric oxide (NO), is a wellestablished marker for the production of reactive nitrogen species and an indirect measurement for inflammation. The innate immune response 
Citation: Menconi A, Kallapura G, Hernandez-Velasco X, Latorre J, Morgan M, et al, (2013) Effect of Glutamine Supplementation Associated with Probiotics on Salmonella Typhimurium and Nitric Oxide or Glutamine with Perinatal Supplement on Growth Performance and Intestinal Morphology in Broiler Chickens. Clin Microbial 2: 120. doi:10.4172/2327-5073.1000120

\begin{tabular}{|l|c|c|c|}
\hline \multicolumn{1}{|c|}{ Treatments } & $\begin{array}{c}\text { Villus height } \\
(\mu \mathrm{m})\end{array}$ & Villus width $(\mu \mathrm{m})$ & $\begin{array}{c}\text { Villus surface area } \\
\text { index }\left(\mu \mathrm{m}^{2}\right)\end{array}$ \\
\hline & & 48 hours & \\
\hline 1. Control & $443.9 \pm 46.5^{\mathrm{b}}$ & $73.7 \pm 6.3^{\mathrm{b}}$ & $101,890 \pm 11,757^{\mathrm{b}}$ \\
\hline 2 EB & $737.4 \pm 27.7^{\mathrm{a}}$ & $118.3 \pm 6.7^{\mathrm{a}}$ & $272,083 \pm 9,253^{\mathrm{a}}$ \\
\hline 3. $0.5 \% \mathrm{Gln}+\mathrm{EB}$ & $801.7 \pm 22.3^{\mathrm{a}}$ & $113.7 \pm 16.5^{\mathrm{a}}$ & $288,554 \pm 4,5475^{\mathrm{a}}$ \\
\hline & & 7 days & \\
\hline 1. Control & $1,108.6 \pm 30.1^{\mathrm{b}}$ & $173.1 \pm 10.4^{\mathrm{a}}$ & $605,798 \pm 51,342^{\mathrm{ab}}$ \\
\hline 2 EB & $1,384.7 \pm 54.5^{\mathrm{a}}$ & $169.7 \pm 13.0^{\mathrm{a}}$ & $742,877 \pm 78,879^{\mathrm{a}}$ \\
\hline 3 0.5 \% Gln + EB & $1,333.4 \pm 40.3^{\mathrm{a}}$ & $126.6 \pm 12.1^{\mathrm{b}}$ & $528,375 \pm 51,378^{\mathrm{b}}$ \\
\hline & & 14 days & \\
\hline 1. Control & $1,318.7 \pm 97.9^{\mathrm{b}}$ & $144.0 \pm 4.4^{\mathrm{b}}$ & $599,454 \pm 55,244^{\mathrm{b}}$ \\
\hline 2. EB & $1,554.9 \pm 36.2^{\mathrm{ab}}$ & $160.2 \pm 19.5^{\mathrm{b}}$ & $788,454 \pm 109,363^{\mathrm{ab}}$ \\
\hline 3. $0.5 \% \mathrm{Gln}+\mathrm{EB}$ & $1,617.7 \pm 120.9^{\mathrm{a}}$ & $217.1 \pm 19.1^{\mathrm{a}}$ & $1,129,650 \pm 176,212^{\mathrm{a}}$ \\
\hline
\end{tabular}

$300 \mathrm{~d}$ of hatch off sex broiler chickens were obtained and randomly distributed in to 3 separate groups $(n=100)$. Treatments were administered according to groups: Group 1, received no treatment; Group 2, received 200 grams of EB only; and Group3 received EB supplemented with $0.5 \%$ L-glutamine. Five duodenum samples/group were collected for enteric morphometric analysis, at all-time points. Values were expressed as means \pm SEM representing 5 birds/group and 10 measurements/parameter/bird. a, b, c Values within columns with no common superscript differ significantly $\mathrm{P}<0.05$.

Table 6: Effect of $0.5 \%$ Glutamine (Gln) with perinatal supplement (EB) on morphometric analysis of the duodenum mucosa of broiler chickens from experiment 4

is modulated through the recruitment of various cellular components upon pathogen exposure. Heterophils, monocytes and macrophages are at the forefront of pathogen recognition, and work in combination with effector leukocytes to initiate an immune response. Studies investigating the role of heterophils, monocytes, and macrophages begin with quantification of reactive nitrogen species (RNS), reactive oxygen species (ROS), along with cytokines and chemokines [46]. Though rapid clearance of pathogens has been attributed to ROS (oxidative stress) rather than RNS (nitrosative stress), nitrosative stress is important in chronic and prolonged exposure. The sequential progression from a predominant oxidative stress to the production of nitrosative clearance could optimize the reduction in microbial burden along with minimizing immune pathological consequences of host inflammatory response $[47,48]$. Hence, quantifying metabolites of nitric oxide (NO), such as nitrite or expression of inducible nitric oxide synthase (iNOS), have been the principle for investigating the role of RNS during host inflammatory responses. The quantification of NO in the ileal explants from experiments 2 and 3 provided a suitable model for inflammation (Table 3 and 4 ), which potentially mimics in vivo intestinal conditions that rapidly detected $\mathrm{NO}(6 \mathrm{~h})$, at a greater magnitude than other cell culture methods [49-51] .

On the other hand, a fasting period of 24 to $72 \mathrm{~h}$ after hatch is a common practice in commercial poultry operations [19] due to variation in hatching time and management in the hatchery. This delay in start of feed intake has been shown to negatively affect yolk utilization [52], gastrointestinal development [15], slaughter weight [53] and breast meat yield $[54,55]$. In addition, delayed feeding seems to depress immunological development [56]. The immediate post-hatch period is critical for intestinal morphological development in order to digest feed and assimilate nutrients [57,58]. Decreased intestinal development in chicks fasted for 36 to 48 hours post-hatch have been extensively reported by several investigators $[9-11,20,59,60]$. In the present study, chicks that received $0.5 \%$ Gln with a perinatal supplement showed significantly less body weight loss during at $24 \mathrm{~h}$ and $48 \mathrm{~h}$ under simulated shipping period of $48 \mathrm{~h}$ and were significantly heavier at 7 and 14 days (Table
5), and these changes were associated with the significant increased $\mathrm{VH}, \mathrm{VW}$, and VS observed in the groups treated with EB only or EB + $\mathrm{Gln}$, when compared to non-treated control group at $24 \mathrm{~h}$. The trend of significant and in some cases numerically, morphometric changes were observed throughout the study in duodenum samples (Table 6). In summary, Gln with probiotics or perinatal supplementation suggest that these nutraceuticals could be a good practical delivery system for this important amino acid during the common fasting conditions, providing several benefits for the poultry industry

\section{References}

1. Reeds PJ, Burrin DG (2000) The gut and amino acid homeostasis. Nutrition 16: 666-668.

2. Blikslager A, Hunt E, Guerrant R, Rhoads M, Argenzio R (2001) Glutamine transporter in crypts compensates for loss of villus absorption in bovine cryptosporidiosis. Am J Physiol Gastrointest Liver Physiol 281: G645-653.

3. Bode BP (2001) Recent molecular advances in mammalian glutamine transport J Nutr 131: 2475S-85S.

4. Liu T, Peng J, Xiong Y, Zhou S, Cheng X (2002) Effects of dietary glutamine and glutamate supplementation on small intestinal structure, active absorption and DNA, RNA concentrations in skeletal muscle tissue of weaned piglets during d 28 to 42 of age. Asian Australasian J Animal Sci 15: 238-242.

5. Soltan M (2009) Influence of dietary glutamine supplementation on growth performance, small intestinal morphology, immune response and some blood parameters of broiler chickens. Int J Poult Sci 8: 60-68.

6. Murakami AE, Sakamoto MI, Natali MR, Souza LM, Franco JR (2007) Supplementation of glutamine and vitamin $E$ on the morphometry of the intestinal mucosa in broiler chickens. Poult Sci 86: 488-495.

7. Fasina YO, Bowers JB, Hess JB, McKee SR (2010) Effect of dietary glutamine supplementation on Salmonella colonization in the ceca of young broiler chicks. Poult Sci 89: 1042-1048

8. Sell JL, Angel CR, Piquer FJ, Mallarino EG, al-Batshan HA (1991) Developmental patterns of selected characteristics of the gastrointestinal tract of young turkeys. Poult Sci 70: 1200-1205.

9. Casteel ET, Wilson JL, Buhr RJ, Sander JE (1994) The influence of extended posthatch holding time and placement density on broiler performance. Poult Sci 73: 1679-1684.

10. Bigot K, Mignon-Grasteau S, Picard M, Tesseraud S (2003) Effects of delayed feed intake on body, intestine, and muscle development in neonate broilers. Poult Sci 82: 781-788.

11. Careghi C, Tona K, Onagbesan O, Buyse J, Decuypere E, et al. (2005) The effects of the spread of hatch and interaction with delayed feed access after hatch on broiler performance until seven days of age. Poult Sci 84: 1314-1320.

12. Hooshmand M (2006) Effect of early feeding programs on broiler performance. Int J Poult Sci 5: 1140-1143.

13. Pinchasov $Y$, Noy $Y$ (1993) Comparison of post-hatch holding time and subsequent early performance of broiler chicks and Turkey poults. $\mathrm{Br}$ Poult Sci 34: 111-120.

14. Uni Z, Smirnov A, Sklan D (2003) Pre- and posthatch development of goble cells in the broiler small intestine: effect of delayed access to feed. Poult Sci 82: $320-327$

15. Noy Y, Geyra A, Sklan D (2001) The effect of early feeding on growth and small intestinal development in the posthatch poult. Poult Sci 80: 912-919.

16. Noy Y, Sklan D (1998) Metabolic responses to early nutrition. J Appl Poult Res 7: 437 .

17. Meltzer A (1983) Thermoneutral zone and resting metabolic rate of broilers. $\mathrm{Br}$ Poult Sci 24: 471-476.

18. van den Brand H, Molenaar R, van der Star I, Meijerhof R (2010) Early feeding affects resistance against cold exposure in young broiler chickens. Poult Sc 89: $716-720$.

19. Dibner J, Knight C, Kitchell M, Atwell C, Downs A, et al. (1998) Early feeding and development of the immune system in neonatal poultry. J Appl Poult Res 7: 425-436. 
Citation: Menconi A, Kallapura G, Hernandez-Velasco X, Latorre J, Morgan M, et al, (2013) Effect of Glutamine Supplementation Associated with Probiotics on Salmonella Typhimurium and Nitric Oxide or Glutamine with Perinatal Supplement on Growth Performance and Intestinal Morphology in Broiler Chickens. Clin Microbial 2: 120. doi:10.4172/2327-5073.1000120

20. Henderson S, Vicente J, Pixley C, Hargis B, Tellez G (2008) Effect of an early nutritional supplement on broiler performance. Int J Poult Sci 7: 211-214.

21. Tellez G, Higgins S, Donoghue A, Hargis B (2006) Digestive physiology and the role of microorganisms. J Appl Poult Res 15: 136-144.

22. Farnell MB, Donoghue AM, de Los Santos FS, Blore PJ, Hargis BM, et al. (2006) Upregulation of oxidative burst and degranulation in chicken heterophils stimulated with probiotic bacteria. Poult Sci 85: 1900-1906.

23. Higgins JP, Higgins SE, Vicente JL, Wolfenden AD, Tellez G, et al. (2007) Temporal effects of lactic acid bacteria probiotic culture on Salmonella in neonatal broilers. Poult Sci 86: 1662-1666.

24. Higgins JP, Andreatti Filho RL, Higgins SE, Wolfenden AD, Tellez G, et al. (2008) Evaluation of Salmonella-lytic properties of bacteriophages isolated from commercial broiler houses. Avian Dis 52: 139-142.

25. Higgins SE, Wolfenden AD, Tellez G, Hargis BM, Porter TE (2011) Transcriptional profiling of cecal gene expression in probiotic- and Salmonellachallenged neonatal chicks. Poult Sci 90: 901-913.

26. Vicente J, Higgins S, Bielke L, Tellez G, Donoghue D, et al. (2007) Effect of probiotic culture candidates on Salmonella prevalence in commercial turkey houses. J Appl Poult Res 16: 471-476.

27. Vicente JL, Torres-Rodriguez A, Higgins SE, Pixley C, Tellez G, et al. (2008) Effect of a selected Lactobacillus spp.-based probiotic on Salmonella enterica serovar enteritidis-infected broiler chicks. Avian Dis 52: 143-146.

28. Wolfenden A, Pixley C, Higgins J, Higgins S, Vicente J, et al. (2007) Evaluation of spray application of a Lactobacillus-based probiotic on Salmonella enteritidis colonization in broiler chickens. Int J Poult Sci 6: 493-496.

29. Wolfenden R, Pumford N, Morgan M, Shivaramaiah S, Wolfenden A, et al. (2010) Evaluation of a screening and selection method for Bacillus isolates for use as effective direct-fed microbials in commercial poultry. Int J Poult Sci 9: 317-323.

30. Wolfenden RE, Pumford NR, Morgan MJ, Shivaramaiah S, Wolfenden AD, et al. (2011) Evaluation of selected direct-fed microbial candidates on live performance and Salmonella reduction in commercial turkey brooding houses. Poult Sci 90: 2627-2631.

31. Shivaramaiah S, Pumford N, Morgan M, Wolfenden R, Wolfenden A, et al. (2011) Evaluation of Bacillus species as potential candidates for direct-fed microbials in commercial poultry. Poult Sci 90: 1574-1580.

32. National Research Council. 1994. Nutrient Requirements of Poultry. 9th rev. ed. Natl. Acad. Press, Washington, DC

33. Aptekmann KP, Baraldi Arton SM, Stefanini MA, Orsi MA (2001) Morphometric analysis of the intestine of domestic quails (Coturnix coturnix japonica) treated with different levels of dietary calcium. Anat Histol Embryol 30: 277-280.

34. Sakamoto M, Murakami A, Silveira T, Fernandes J, de Oliveira C (2006) Influence of glutamine and vitamin $\mathrm{E}$ on the performance and the immune responses of broiler chickens. Revista Brasileira de Ciência Avicola 8: 243-249.

35. SAS Institute. 2002. SAS User Guide. Version 9.1. SAS Institute Inc., Cary, NC.

36. Zar J (1984) Biostatistical Analysis. 2nd ed. Prentice Hall, Upper Saddle River, NJ.

37. Kim SW, Wu G (2004) Dietary arginine supplementation enhances the growth of milk-fed young pigs. J Nutr 134: 625-630.

38. Fraune S, Bosch TC (2010) Why bacteria matter in animal development and evolution. Bioessays 32: 571-580

39. Bäckhed F (2011) Programming of host metabolism by the gut microbiota. Ann Nutr Metab 58 Suppl 2: 44-52.

40. Musso G, Gambino R, Cassader M (2010) Obesity, diabetes, and gut microbiota: the hygiene hypothesis expanded? Diabetes Care 33: 2277-2284.

41. Neish AS (2009) Microbes in gastrointestinal health and disease. Gastroenterology 136: 65-80
42. Salzman NH (2011) Microbiota-immune system interaction: an uneasy alliance. Curr Opin Microbiol 14: 99-105.

43. Kau AL, Ahern PP, Griffin NW, Goodman AL, Gordon JI (2011) Human nutrition, the gut microbiome and the immune system. Nature 474: 327-336.

44. Maslowski KM, Mackay CR (2011) Diet, gut microbiota and immune responses. Nat Immunol 12: 5-9.

45. Dai SF, Wang LK, Wen AY, Wang LX, Jin GM (2009) Dietary glutamine supplementation improves growth performance, meat quality and colour stability of broilers under heat stress. Br Poult Sci 50: 333-340.

46. Crippen TL, Sheffield CL, He H, Lowry VK, Kogut MH (2003) Differential nitric oxide production by chicken immune cells. Dev Comp Immunol 27: 603-610.

47. Chakravortty D, Hensel M (2003) Inducible nitric oxide synthase and control of intracellular bacterial pathogens. Microbes Infect 5: 621-627.

48. Vazquez-Torres A, Fang FC (2001) Oxygen-dependent anti-Salmonella activity of macrophages. Trends Microbiol 9: 29-33.

49. Qureshi MA (2003) Avian macrophage and immune response: an overview. Poult Sci 82: 691-698.

50. He H, Genovese KJ, Swaggerty CL, Nisbet DJ, Kogut MH (2008) Differential induction of nitric oxide, degranulation, and oxidative burst activities in response to microbial agonist stimulations in monocytes and heterophils from young commercial turkeys. Vet Immunol Immunopathol 123: 177-185.

51. Setta A, Barrow PA, Kaiser P, Jones MA (2012) Immune dynamics following infection of avian macrophages and epithelial cells with typhoidal and nontyphoidal Salmonella enterica serovars; bacterial invasion and persistence nitric oxide and oxygen production, differential host gene expression, NF-kB signalling and cell cytotoxicity. Vet Immunol Immunopathol 35: 397-410.

52. Noy Y, Sklan D (2001) Yolk and exogenous feed utilization in the posthatch chick. Poult Sci 80: 1490-1495.

53. Halevy O, Geyra A, Barak M, Uni Z, Sklan D (2000) Early posthatch starvation decreases satellite cell proliferation and skeletal muscle growth in chicks. $J$ Nutr 130: 858-864.

54. Noy Y, Uni Z (2010) Early nutritional strategies. World's Poult Sci J 66:639

55. Halevy O, Nadel Y, Barak M, Rozenboim I, Sklan D (2003) Early posthatch feeding stimulates satellite cell proliferation and skeletal muscle growth in turkey poults. J Nutr 133: 1376-1382.

56. Juul-Madsen HR, Su G, Sørensen P (2004) Influence of early or late start of first feeding on growth and immune phenotype of broilers. Br Poult Sci 45 210-222.

57. Uni Z, Noy Y, Sklan D (1999) Posthatch development of small intestinal function in the poult. Poult Sci 78: 215-222.

58. Uni Z, Tako E, Gal-Garber O, Sklan D (2003) Morphological, molecular, and functional changes in the chicken small intestine of the late-term embryo. Poult Sci 82: 1747-1754

59. Batal AB, Parsons CM (2002) Effect of fasting versus feeding oasis after hatching on nutrient utilization in chicks. Poult Sci 81: 853-859.

60. Uni Z, Ganot S, Sklan D (1998) Posthatch development of mucosal function in the broiler small intestine. Poult Sci $77:$ 75-82. 